\title{
Regulation of IL-1 $\beta$ generation by Pseudo-ICE and ICEBERG, two dominant negative caspase recruitment domain proteins
}

\author{
A Druilhe ${ }^{1,2}$, SM Srinivasula ${ }^{1}$, M Razmara $^{1}$, M Ahmad $^{1,3}$ and \\ ES Alnemri ${ }^{\star, 1}$ \\ 1 Center for Apoptosis Research and the Department of Microbiology and \\ Immunology, Kimmel Cancer Institute, Thomas Jefferson University, \\ Philadelphia, PA 19107, USA \\ ${ }^{2}$ Current address: INSERM U408, Faculté de Médecine Xavier Bichat, Paris, \\ France \\ ${ }^{3}$ Current address: Laboratory of Immunology, NIAID/NIH Building 10, Room 11 \\ D09, 9000 Rockville Pike, Bethesda MD 20892, USA \\ * Corresponding author: ES Alnemri, Thomas Jefferson University, Kimmel \\ Cancer Institute, Bluemle Life Sciences Buidling, room 904, 233 S. 10th Street, \\ Philadelphia, PA, 19107, USA. Tel: 215-503-4632; Fax: 215-923-1098; \\ E-mail: E_Alnemri@lac.jci.tju.edu
}

Received 22.2.01; revised 15.3.01; accepted 16.3.01 Edited by D Green

\begin{abstract}
We report here the identification and functional characterization of two new human caspase recruitment domain (CARD) molecules, termed Pseudo-interleukin- $1 \beta$ converting enzyme (ICE) and ICEBERG. Both proteins share a high degree of homology, reaching $92 \%$ and $53 \%$ identity, respectively, to the prodomain of caspase-1/ICE. Interestingly, both Pseudo-ICE and ICEBERG are mapped to chromosome 11q22 that bears caspases-1, -4- and -5 genes, all involved in cytokine production rather than in apoptosis. We demonstrate that Pseudo-ICE and ICEBERG interact physically with caspase-1 and block, in a monocytic cell line, the interferon- $\gamma$ and lipopolysaccharide-induced secretion of interleukin- $1 \beta$ which is a well-known consequence of caspase- 1 activation. Moreover, Pseudo-ICE, but not ICEBERG, interacts with the CARD-containing kinase RICK/RIP2/CARDIAK and activates NF- $k$ B. Our data suggest that Pseudo-ICE and ICEBERG are intracellular regulators of caspase-1 activation and could play a role in the regulation of IL- $1 \beta$ secretion and NF- $\kappa$ B activation during the pro-inflammatory cytokine response. Cell Death and Differentiation (2001) 8, 649-657.
\end{abstract}

Keywords: caspase-1; inflammation; NF- $\kappa \mathrm{B}$; protein interaction; cloning

Abbreviations: CARD, caspase recruitment domain; DED, death effector domain; EST, expressed sequence tag; GST, glutathioneS-transferase; HTGS, Genbank unfinished High Throughput Genomic Sequences; ICE, interleukin-1- $\beta$ converting enzyme; IFN, interferon; IKK, I $\kappa$ B kinase; IL, interleukin; LPS, lipopolysaccharide; NF, nuclear factor; RICK, RIP-like interacting CLARP kinase; TNF, tumor necrosis factor

\section{Introduction}

Caspase-1, also known as interleukin- $1 \beta$ converting enzyme (ICE), was initially defined as the protease responsible for the processing of the inactive precursor of interleukin (IL)-1 $\beta$ into its active pro-inflammatory form. ${ }^{1,2}$ Caspase- 1 was then shown to be able to process IL-18, a costimulatory factor for another pro-inflammatory cytokine, interferon (IFN)- $\gamma .^{3}$ The proinflammatory role of caspase-1 was strengthened by the results revealed by gene targeting experiments. ${ }^{4-6}$ Caspase1 deficiency in mice is indeed associated with a major defect in IL-1 $\beta$ production in vivo accompanied by a resistance to endotoxic shock and to a decrease of experimental pancreatitis severity and to survival benefits. ${ }^{4,6}$ The production of IFN- $\gamma$ was shown to be markedly impaired in lipopolysaccharide (LPS)-stimulated splenocytes from caspase-1-deficient mice. ${ }^{7}$ Moreover, a reduction of the incidence and severity of experimental autoimmune encephalomyelitis paralleled to a defective production of IFN- $\gamma$ was observed in caspase-1 knock-out animals. ${ }^{8}$

Subsequent to the discovery of caspase-1, ced-3, a nematode gene that encodes a protein essential for all 131 programmed cell deaths that occur during the hermaphrodite development of the nematode $C$. elegans was cloned. $^{9,10}$ The sequence of CED-3 protein revealed its high homology to caspase-1. ${ }^{9}$ This finding led different groups to search in nucleic acid databases for sequences homologous to ced-3 or caspase-1. ${ }^{11,12}$ Using this strategy, 12 human caspases have been cloned to date. ${ }^{13}$ Based on their sequence and their in vitro and in vivo functions, these caspases have been divided into three major subfamilies. ${ }^{12}$ The first group contains the caspases- $1,-4,-5$ and -13 that possess a long pro-domain and are likely to play a role in inflammation by participating in the maturation of cytokines. $^{12}$ The second and third groups are composed of caspases playing a role in apoptosis. ${ }^{12}$ Some of them, defined as effector caspases, such as caspase-3, have a short prodomain and become active following their cleavage by other caspases. This notion is well exemplified by caspase-8 or caspase-9-induced activation of caspase-3 in Fas-mediated apoptosis or in Apaf-1/ cytochrome $c$ pathway, respectively. ${ }^{14-17}$ The other apoptogenic caspases, that bear a long prodomain, like caspases- 8 or -9 , are activated by clustering-mediated autoprocessing. ${ }^{18-20}$ Indeed the long prodomain of caspases are characterized by the presence of specific motifs, called death effector domain (DED) and caspase recruitment domain (CARD), that form six antiparallel helices and mediate homotypic binding. ${ }^{21}$ Caspase- 8 possesses a DED that allows the binding to the DED of the adaptor FADD which itself associates with the death receptor Fas. ${ }^{20}$ The induced-proximity of several caspase- 8 
zymogen forms facilitates the autoprocessing of this protease. $^{19,20}$ Similarly, the complex Apaf-1/cytochrome $c /$ dATP induces caspase- 9 activation via the direct binding of their respective CARD. ${ }^{17,18}$

Despite the fact that caspase-1 was the first discovered caspase, the mechanisms leading to its activation have been barely investigated. Oligomerization has been proposed to be a prerequisite for caspase- 1 activation by autoprocessing. ${ }^{22}$ The only protein known so far that is able to bind to the CARD containing prodomain of caspase- 1 is the CARD protein, RIP-like interacting CLARP kinase (RICK/RIP2/CARDIAK). ${ }^{23,24}$ Interestingly, the ectopic expression of RICK was shown to induce the cleavage of caspase-1 presumably by provoking its oligomerization. ${ }^{23,24}$

Based on what is known about the activation of long prodomain caspases, such as caspase-9, we hypothesize that CARD-containing proteins could regulate caspase-1 function. The aim of our study was therefore to identify potential new regulators of caspase- 1 activation by searching databases for sequences homologous to the prodomain of caspase-1. This strategy, that has been proven successful for the identification of many DED and CARD molecules, ${ }^{21}$ led us to the cloning and the functional characterization of two new proteins, termed Pseudo-ICE and ICEBERG.

\section{Results and Discussion}

\section{Identification of Pseudo-ICE and ICEBERG}

To identify potential regulators of caspase-1 activity, we searched public databases of expressed sequence tags (EST) for clones that are significantly homologous to the prodomain of human caspase-1/ICE- $\alpha$ (residues 1-103). Using this strategy, two ESTs (Genbank accession numbers AA046000 and AA070591) encoding two novel open reading frames with high degree of homology to the prodomain of caspase-1 were found.

EST clone AA046000 contains a 273 bp open reading frame that codes for a 90-residue protein with a predicted molecular mass of $10.1 \mathrm{kDa}$ (Figure $1 \mathrm{~A}$ ). This protein is $53 \%$ identical to the CARD domain of human caspase-1 and $100 \%$ identical to ICEBERG. ICEBERG was recently cloned by Humke et al. ${ }^{24}$ while this work was in progress and thus we named the new protein ICEBERG.

The other EST clone (AA070591) comprises a full length 294 bp open reading frame as evident from the presence of a stop codon upstream of the initiator ATG (data not shown). This sequence encodes a 97-residue protein, named Pseudo-ICE, whose expected molecular weight is $10.7 \mathrm{kDa}$ (Figure 1A). Nucleic acid sequences of PseudoICE and caspase-1 prodomain are $97 \%$ identical. PseudoICE is $\sim 92 \%$ identical to caspase-1 prodomain at the protein level.

Because Pseudo-ICE exhibits high degree of sequence identity to caspase-1, we were unable to analyze its tissue distribution by Northern blot. Therefore, to determine the tissue distribution of Pseudo-ICE mRNA, we performed RT-PCR analysis using a primer (primer 2) complementary to the $3^{\prime}$ untranslated region of Pseudo-ICE cDNA which differs from caspase-1 sequence and another primer corresponding to the first $18 \mathrm{bp}$ (primer 1) of Pseudo-ICE open reading frame (Figure 1B). RT-PCR analysis of multiple tissues and cell line mRNAs with primers 1 and 2 revealed that Pseudo-ICE is expressed mainly in placenta, spleen, lymph node and bone marrow tissues and in the monocytic THP1 cell line (Figure 1D). Sequence analysis of the RT-PCR products from the positive tissues and the THP1 cell line revealed an entire open reading frame identical to that of Pseudo-ICE. Identical distribution was observed for caspase-1, suggesting that Pseudo-ICE and caspase-1 are under similar transcriptional regulation. In contrast to caspase-1 and Pseudo-ICE, ICEBERG mRNA was detected mainly in placenta and to a lesser extent in heart (Figure 1D), consistently with Humke et al. ${ }^{24}$ observations. ICEBERG mRNA was also found in many human cell lines (Figure 1D).

In order to determine the putative chromosomal localization of Pseudo-ICE and ICEBERG genes, the Genbank unfinished High Throughput Genomic Sequences (HTGS) database was searched. Pseudo-ICE sequence matches the sequence of three HTGS clones (accession numbers AC027011, AP001153, AP002787) that are mapped in locus 11q22 suggesting that Pseudo-ICE gene is located on chromosome 11. The comparison between Pseudo-ICE sequence and the working draft sequence of HTGS clones revealed that Pseudo-ICE gene is composed of at least three exons (Figure 1C). ICEBERG sequence also matched the sequences of two HTGS clones on chromosome 11q22 (AC027011 and AC023068). Moreover, it is noteworthy that the sequences of caspases-1, -4 and -5 , that belong to the same phylogenic and functional subfamily of caspases, ${ }^{12,13}$ are also found in the same locus (data not shown).

\section{Pseudo-ICE and ICEBERG interact with caspase-1}

Based on sequence homology to the prodomain of caspase1 , that roughly corresponds to its CARD, ${ }^{21}$ Pseudo-ICE and ICEBERG can be defined as CARD proteins. Since CARD domain is known to mediate protein interaction through homophilic binding, ${ }^{21}$ we decided to test whether PseudoICE or ICEBERG could bind to caspase-1. To do this, we incubated ${ }^{35} \mathrm{~S}$-labeled caspase-1 with glutathione S-transferase (GST), GST-conjugated Pseudo-ICE or ICEBERG bound to resin (Figure 2A). GST-conjugated Pseudo-ICE or ICEBERG, but not GST alone, were able to interact strongly with ${ }^{35}$ S-labeled caspase-1 in vitro (Figure 2B). GST-PseudoICE and ICEBERG were also able to interact with ${ }^{35}$ S-labeled Pseudo-ICE and ICEBERG, suggesting that these proteins can self-associate and can interact with each other (Figure 2B). In vivo binding assays also confirmed the ability of Pseudo-ICE and ICEBERG to self-associate (Figure 2C).

The interactions described above are specific since neither Pseudo-ICE, nor ICEBERG coprecipitated in vitro or in vivo other CARD-containing proteins tested, comprising caspases-2, -4, and -9, Apaf-1, CRADD, c-CLAP, and cIAP2 (Figure $2 \mathrm{C}$ and data not shown). It is noteworthy that Pseudo-ICE and ICEBERG did not interact either with caspases-8 or -10 , or with FADD, which contain DEDs and/ 


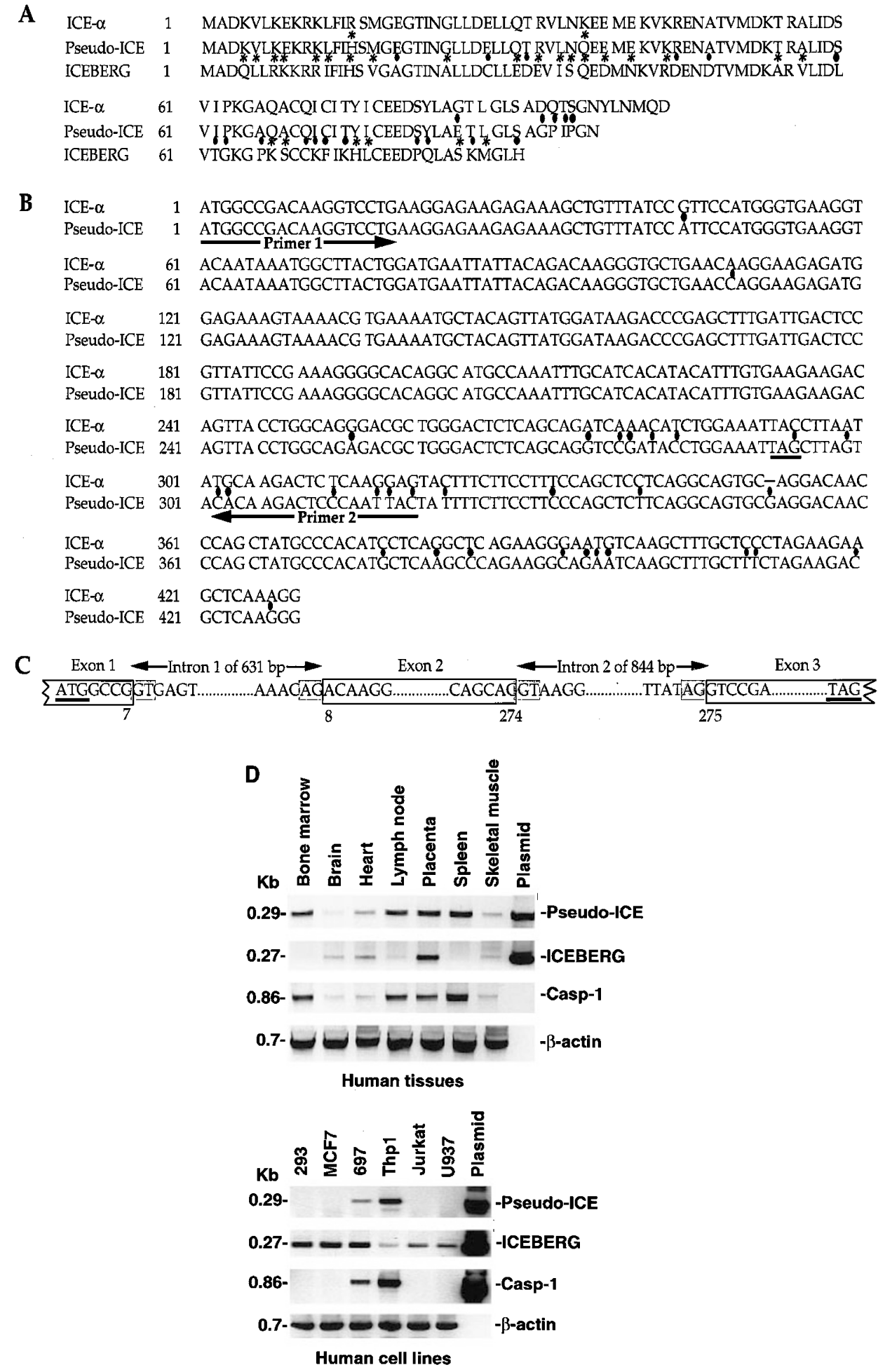

Figure 1 Amino acid and nucleotide sequences of Pseudo-ICE, ICEBERG and caspase-1 prodomain and structure of Pseudo-ICE gene. (A) Multiple sequence alignment of the prodomain of human caspase-1/ICE- $\alpha$, Pseudo-ICE, and ICEBERG. Conserved residues and non-conserved substitutions are indicated by $(\boldsymbol{t})$ and $(\bullet)$, respectively. (B) Colinear alignment of caspase-1 prodomain and Pseudo-ICE nucleotide sequences, including the 3 , untranslated region of Pseudo-ICE. Primers 1 and 2 were used to amplify Pseudo-ICE from various tissue and cell line mRNAs by RT-PCR. Stop codon of Pseudo-ICE is underlined. Base differences are indicated by $(\bullet)$. (C) Putative structure of Pseudo-ICE gene. Exons are boxed. $5^{\prime}$ splicing donor and $3^{\prime}$ splicing acceptor are shaded. The ATG and the stop codons are underlined. The base pair numbers, corresponding to the numbers in (B), are indicated under the exon boxes. (D) Tissue distribution of Pseudo-ICE, ICEBERG and caspase-1 mRNA. Total RNA samples from different human tissues (upper panels) and cell lines (lower panels) were amplified by RT-PCR with primers specific for Pseudo-ICE, ICEBERG, caspase-1 and $\beta$-actin and then analyzed on agarose gel and stained with ethidium bromide. Plasmids (plasmid lanes) containing Pseudo-ICE and ICEBERG (upper panels) or Pseudo-ICE, ICEBERG or caspase-1 (lower panels) were used as control templates for the PCR reactions 


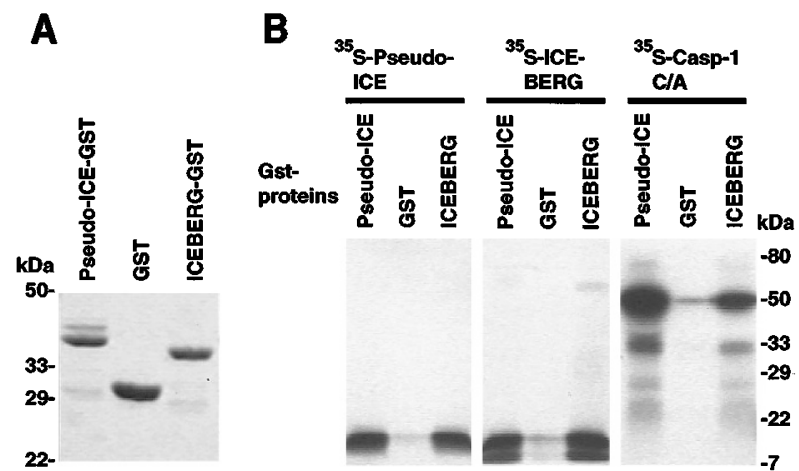

C

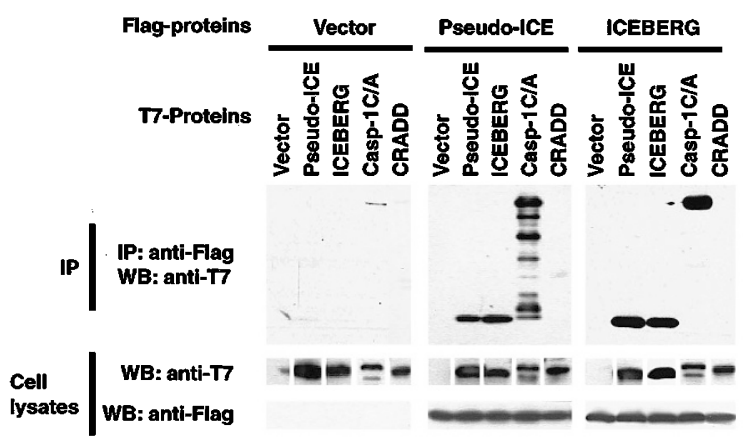

Figure 2 In vitro and in vivo interactions of Pseudo-ICE and ICEBERG with caspase-1. (A) GST, Pseudo-ICE-GST and ICEBERG-GST were expressed in $E$. coli $\mathrm{DH} 5-\alpha$ and then bound to gluthatione sepharose resin. The purity of GST-fusion proteins was determined by polyacrylamide gel analysis followed by Coomassie staining. (B) Pseudo-ICE-GST, GST and ICEBERG-GST bound to gluthatione resins were incubated in the presence of in vitro translated ${ }^{35} \mathrm{~S}$ labeled Pseudo-ICE, ICEBERG or caspase-1 C to A (Casp-1 C/A). The bound proteins were eluted with sample buffer and analyzed by polyacrylamide gel followed by autoradiography. (C) $293 \mathrm{~T}$ cells were transiently cotransfected with equal amounts (total DNA of $10 \mu \mathrm{g} / \mathrm{dish}$ ) of expression constructs encoding T7-tagged Pseudo-ICE, ICEBERG, caspase-1 C to A, or CRADD and Flag-tagged Pseudo-ICE or ICEBERG or an empty vector control. After $36 \mathrm{~h}$, extracts were prepared and immunoprecipitated with a monoclonal antiFlag antibody. The immunoprecipitates (IP; upper panel) and the corresponding cellular lysates (middle panel) were analyzed by polyacrylamide gel and immunoblotted with a horseradish peroxidase-conjugated anti-T7 antibody. The cellular extracts (lower panel) were also blotted with an anti-Flag antibody followed by horseradish peroxidase-conjugated secondary antibody and chemiluminescence detection. WB stands for Western blot. Molecular weight markers are shown on the right or the left of the panels in $(\mathbf{A})$ and $(\mathbf{B})$, respectively. The films displayed in this figure are representative of at least three experiments

or death domains structurally and functionally related to CARD $^{21}$ (data not shown).

\section{Pseudo-ICE and ICEBERG prevent binding of caspase-1 to RICK}

RICK has been shown to bind caspase- 1 through CARDCARD interaction and to induce its processing. ${ }^{23}$ To determine whether Pseudo-ICE and ICEBERG can interact with RICK, we transfected 293 T cells with Flag-tagged RICK and T7-tagged Pseudo-ICE or ICEBERG and immunoprecipitated the complexes with an anti-Flag antibody. As shown in Figure 3A, caspase-1 and Pseudo-ICE but not ICEBERG were able to interact with RICK. Similar results were obtained by in vitro interaction assays with ${ }^{35} \mathrm{~S}$-labeled RICK and GST fusion proteins of caspase-1-CARD, Pseudo-ICE or ICEBERG (data not shown). The ability of Pseudo-ICE to interact with RICK was expected based on the high degree of homology between the CARD of caspase-1, which mediates its interaction with RICK, and Pseudo-ICE. The absence of any interaction between ICEBERG and RICK is consistent with the results described recently by Humke et al. ${ }^{24}$

To determine whether expression of Pseudo-ICE and ICEBERG affects the interaction between RICK and caspase-1, we performed in vivo interaction assays between RICK and caspase-1 in the presence or absence of increasing amounts of Pseudo-ICE and ICEBERG. Both Pseudo-ICE and ICEBERG prevented binding of caspase-1 to RICK in a dose dependent manner, although the effect of Pseudo-ICE was more dramatic (Figure 3B). These results indicate that the CARD-CARD interactions between caspase-1 and Pseudo-ICE or ICEBERG interfere with

A

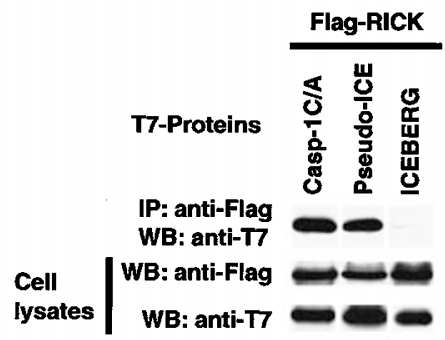

B

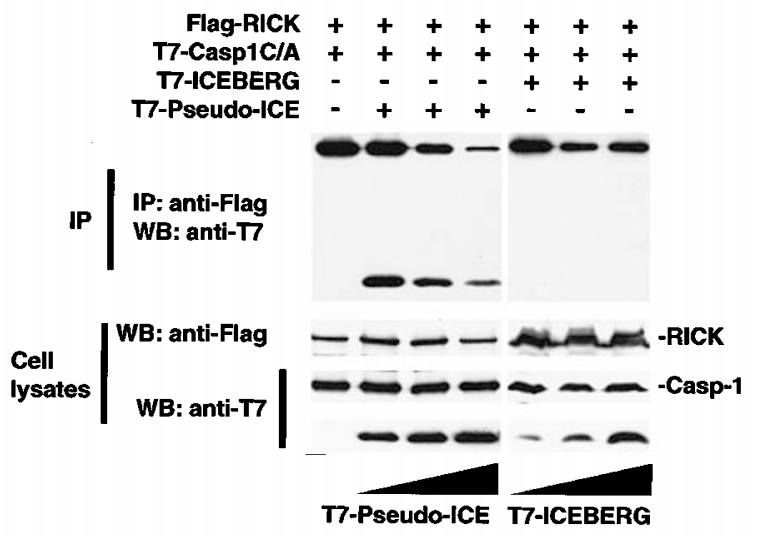

Figure 3 In vivo interactions of Pseudo-ICE and ICEBERG with RICK. (A) $293 \mathrm{~T}$ cells were cotransfected with equal amounts (total DNA of $10 \mu \mathrm{g} / \mathrm{dish}$ ) of pcDNA3 encoding T7-tagged Pseudo-ICE, ICEBERG, or caspase-1 C to A (Casp-1 C/A) and Flag-tagged RICK. After $36 \mathrm{~h}$, extracts were prepared, immunoprecipitated and analyzed as in Figure $2 \mathrm{C}$ legend. (B) $293 \mathrm{~T}$ cells were cotransfected with constructs encoding Flag-RICK $(2.5 \mu \mathrm{g})$ and T7-caspase 1 $\mathrm{C}$ to $\mathrm{A}(2 \mu \mathrm{g})$ together with increasing amounts $(2,5,8 \mu \mathrm{g})$ of T7-Pseudo-ICE or T7-ICEBERG constructs. Samples were then processed as described in the legend of Figure 2C. IP and WB stand for immunoprecipitate and Western blot, respectively. The films displayed in this figure are representative of at least three experiments 
binding of caspase-1 to RICK. Moreover, the ability of Pseudo-ICE to interact with RICK could further decrease the binding of caspase-1 to RICK.

\section{Pseudo-ICE and ICEBERG inhibit the induced secretion of IL-1 $\beta$ in THP1 monocytic cell line}

To investigate the role of Pseudo-ICE and ICEBERG in IL-1 $\beta$ secretion, which is a well-known consequence of caspase-1 activation, ${ }^{2,4,5}$ we generated stable transfectants of THP1 cells expressing T7-epitope tagged Pseudo-ICE, ICEBERG, or caspase-1 $\mathrm{C}$ to $\mathrm{A}$ active site mutant using a retroviral gene transfer technology. As shown in Figure 4A, all stable transfectants expressed detectable amounts of Pseudo-ICE, ICEBERG and caspase-1 C to A. Interestingly, expression of caspase-1 C/A or ICEBERG reduced by around $80 \%$ the secretion of IL-1 $\beta$, whereas expression of Pseudo-ICE completely blocked the release of IL-1 $\beta$ in response to IFN- $\gamma$ and LPS, suggesting strongly that these proteins block specifically ICE activation (Figure 4B). No significant effect by these proteins was observed on secretion of IL-1 receptor

A

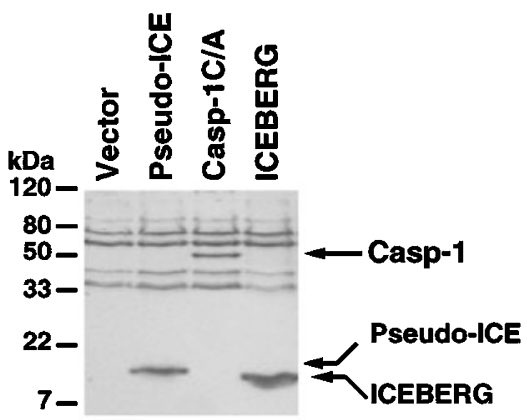

B

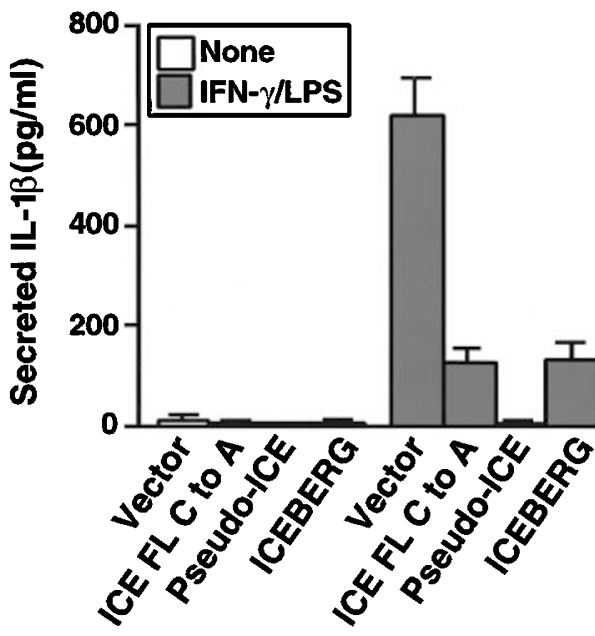

Figure 4 Inhibition of IL-1- $\beta$ secretion by Pseudo-ICE and ICEBERG. THP1 cells were infected using a retroviral vector encoding T7-epitope tagged Pseudo-ICE, ICEBERG or caspase-1 $C$ to $A(C a s p-1 C / A)$ and a gene of resistance to neomycin. After selection with neomycin antibiotic, stable transfectant THP1 mass cultures were assayed for the expression of T7epitope tagged proteins by Western blot as shown in (A). THP1 cells were then treated with or without IFN- $\gamma$ and LPS for $22 \mathrm{~h}$. IL-1 $\beta$ was quantified in the supernatant of culture. The results, expressed as mean \pm S.E.M. of three experiments, are shown in (B) antagonist (data not shown), another cytokine that is secreted from THP1 in response to IFN- $\gamma$ and LPS. ${ }^{25}$ Furthermore, treatment with IFN- $\gamma$ and LPS of the same number of uninfected or mock-infected (vector) THP1 cells induced the secretion of the same amount of IL-1 $\beta$, i.e. $585.2 \pm 102.7$ and $629.8 \pm 69.1 \mathrm{pg} / \mathrm{ml}$, respectively (mean \pm S.E.M., $n=7$ and 3 , respectively). These results indicate that retroviral infection followed by selection has not modified the ability of THP1 cells to respond to IFN- $\gamma$ and LPS. Taken together, our results demonstrate that Pseudo-ICE and ICEBERG reduce $\mathrm{IL}-1 \beta$ secretion, probably by binding to the prodomain of caspase- 1 thereby preventing its activation by RICK or another novel caspase-1 activator.

\section{Pseudo-ICE and ICEBERG do not induce apoptosis in MCF-7 Fas cells}

The ectopic expression of the prodomain of caspase- 1 was shown to induce cell death in MCF-7 cells presumably because of the ability of the caspase- $1 \mathrm{~N}$-terminal end to translocate to the nucleus. ${ }^{26}$ According to Mao et al., ${ }^{26}$ a lysine/arginine rich segment at residues 4-11 (KVLKEKRK) that resembles a nuclear localization signal, would be responsible for caspase-1 prodomain nuclear translocation. Despite of the highly conserved sequence, especially at residues 4-11, of Pseudo-ICE, this protein did not induce significant apoptosis when overexpressed in MCF-7 Fas cells and did not affect tumor necrosis factor (TNF)- $\alpha$-induced apoptosis (Figure 5). Similarly to Pseudo-ICE and unlike to caspase-9 $\mathrm{C}$ to $\mathrm{A}$, ICEBERG ectopic expression had no significant effects on basal or TNF- $\alpha$-induced cell death in MCF-7 Fas cells (Figure 5). Moreover, transiently expressed Pseudo-ICE and ICEBERG conjugated in $\mathrm{N}$ or $\mathrm{C}$ terminal of enhanced green fluorescent protein were evenly distributed in the cytoplasm, but not in the nucleus, of MCF-7 Fas cells treated or not by TNF- $\alpha$ (data not shown). Interestingly, in a

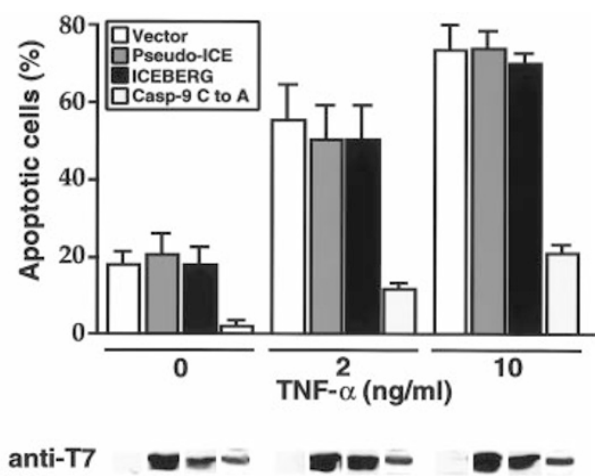

Figure 5 Effect of Pseudo-ICE and ICEBERG on spontaneous and TNF- $\alpha$ induced apoptosis. Triplicate of MCF-7 Fas cells were transiently transfected with pcDNA3 vector encoding T7-epitope tagged Pseudo-ICE, ICEBERG or caspase-9 (Casp-9) C to A together with pRSC-lacZ. Cells were incubated for $12 \mathrm{~h}$ in the absence or in the presence of 2 or $10 \mathrm{ng} / \mathrm{ml}$ of TNF- $\alpha$ and were then stained in situ for $\beta$-galactosidase activity. The proportions of apoptotic cells were evaluated by counting the numbers of blue-stained normal and apoptotic cells in two wells. The cells from the third remaining well were collected and used to verify by Western blot the expression of the transgenes. Results are 
few cells, cytoplasmic filaments were observed (data not shown). Similar filaments have been described in cells overexpressing members of the superfamily of six helix bundle interaction domain such as caspase-8 DED, FADD DED and c-CLAP CARD. ${ }^{21,27,28}$

\section{Pseudo-ICE, but not ICEBERG, induces nuclear factor (NF)- $\kappa$ B activation in 293 T cells}

Several CARD-containing proteins, including RICK, have been shown to regulate NF- $\kappa$ B activation. ${ }^{23,29-37}$ In keeping with this notion, we hypothesized that Pseudo-ICE and ICEBERG might regulate this activity. $293 \mathrm{~T}$ cells were thus transfected with constructs encoding Pseudo-ICE or ICE-

A

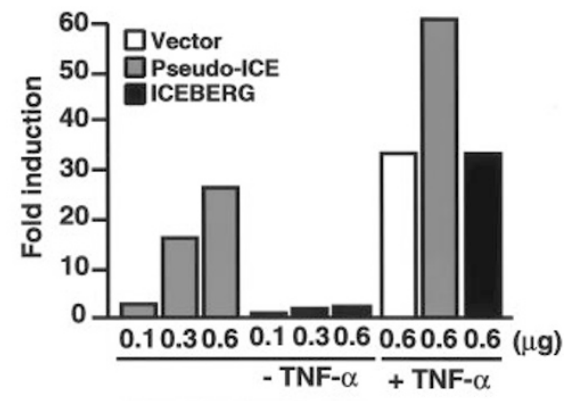

WB : anti-T

B

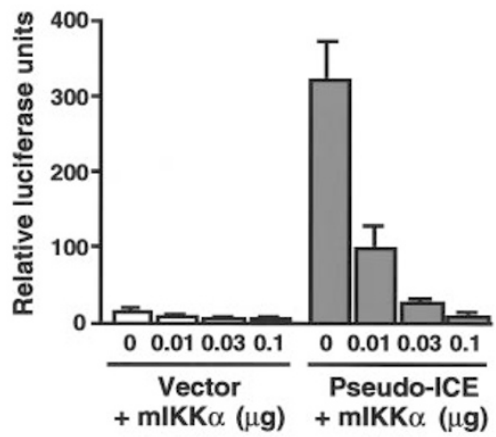

T7-Pseudo-ICE

Figure 6 Effect of ectopic expression of Pseudo-ICE and ICEBERG on NF$\kappa \mathrm{B}$ activation. $293 \mathrm{~T}$ cells were transiently cotransfected with expression vectors pcDNA3 or pCMV2 encoding T7- or Flag-epitope tagged proteins respectively, together with $\mathrm{NF}-\kappa \mathrm{B}$ luciferase reporter construct and $\mathrm{pRSC}$ lacZ. In each well, the total amount of plasmid was kept constant by addition of pcDNA3 or pCMV2. NF- $\kappa \mathrm{B}$ and $\beta$-galactosidase activities were assayed in cel extracts. The expression of $\mathrm{T} 7$ and Flag-epitope tagged proteins was verified by Western blot as shown below graphs. (A) $293 \mathrm{~T}$ cells were transfected with $0.6 \mu \mathrm{g}$ of empty vector or with $0.1,0.3$, or $0.6 \mu \mathrm{g}$ of constructs encoding $\mathrm{T} 7$ epitope tagged Pseudo-ICE, or ICEBERG. Before being lysed, the cells were treated with or without TNF- $\alpha$. The results are expressed as fold induction of $\mathrm{NF}-\kappa \mathrm{B}$ activity as compared to that of $293 \mathrm{~T}$ transfected with empty vector and TNF- $\alpha$-untreated. Data shown are representative of at least three experiments. (B) $293 \mathrm{~T}$ cells were transfected with equal amount $(0.6 \mu \mathrm{g})$ of pcDNA3 T7Pseudo-ICE and with increasing quantities $(0.01,0.03,0.1 \mu \mathrm{g})$ of pCMV2 Flag kinase inactive mutant of $\mathrm{IKK}-\alpha(\mathrm{mIKK}-\alpha)$. The results are expressed as relative luciferase units normalized for $\beta$-galactosidase activity. The bars represent mean + S.E.M. of triplicate. Data shown are representative of at least three experiments
BERG together with a NF- $\kappa \mathrm{B}$ driven luciferase reporter plasmid in the presence or absence of TNF- $\alpha$. Pseudo-ICE strongly activated NF- $\kappa \mathrm{B}$ in a dose-dependent manner and enhanced TNF- $\alpha$-induced NF- $\kappa \mathrm{B}$ activation (Figure 6A). At levels of expression comparable to that of Pseudo-ICE, ICEBERG had very little effect on the basal or TNF- $\alpha$-induced $\mathrm{NF}-\kappa \mathrm{B}$ activity (Figure $6 \mathrm{~A}$ ). This suggests that NF- $\kappa \mathrm{B}$ activity is unlikely to be provoked by a non-specific cellular stress mediated by transient expression of Pseudo-ICE. This stress termed the endoplasmic reticulum-overload response has been described by $\mathrm{Pahl}$ et $\mathrm{al}^{38}$ Finally, a kinase inactive mutant of $I_{\kappa} B$ kinase (IKK)- $\alpha$ dose-dependently inhibited NF$\kappa \mathrm{B}$ activity provoked by Pseudo-ICE without modifying its expression as shown in Figure 6B. Combined, these results indicate that Pseudo-ICE activates NF- $\kappa$ B via a mechanism dependent on the IKK complex. ${ }^{39}$

In conclusion, we have identified and characterized the functions of two novel human molecules, termed PseudoICE and ICEBERG, that show striking similarities to the pro-domain of caspase-1 and thus belong to the growing family of CARD-containing proteins. We showed that Pseudo-ICE and ICEBERG inhibit the secretion of IL-1 $\beta$ in THP1 monocytic cell line. This effect is presumably mediated by the ability of both proteins to interact strongly with the prodomain of caspase- 1 thereby preventing the binding of an activator of this caspase. This notion is supported by the finding that Pseudo-ICE and ICEBERG prevent binding of caspase-1 to RICK, which was shown by Thome et al. ${ }^{23}$ and Humke et al. ${ }^{24}$ to interact with and provoke the processing of caspase-1. Humke et al. ${ }^{24}$ also demonstrated that endogenous ICEBERG inhibits caspase1 oligomerization induced by RICK. In this respect, PseudoICE and ICEBERG are similar to the inhibitor of caspase-8, FLAME/FLIP, that contains DED domains and inhibits caspase- 8 autoprocessing by preventing its association with the DED-containing adaptor FADD. ${ }^{21}$ Of note, except for Pseudo-ICE and ICEBERG, all the CARD proteins described so far bear at least one additional domain which defines the function of the protein either as an enzyme, kinase or caspase, or as an adaptor. ${ }^{21}$ The absence of this additional domain makes Pseudo-ICE and ICEBERG unlikely to play a role as an adaptor and thereby as an activator for caspase-1. In contrast, Pseudo-ICE and ICEBERG may act as decoy or dominant negative inhibitory molecules.

In addition to its activity as a dominant negative inhibitor of caspase-1, our results clearly show also that Pseudo-ICE, but not ICEBERG, activates NF- $\kappa \mathrm{B}$, thus extending the growing subgroup of CARD-containing proteins involved in $\mathrm{NF}-\kappa \mathrm{B}$ pathway. ${ }^{23,29-35,39}$ The mechanisms leading to NF- $\kappa \mathrm{B}$ activation after PseudoICE overexpression or after other CARD protein ectopic expression are still elusive and require further investigation. However, since Pseudo-ICE, but not ICEBERG, interacts with the CARD-containing kinase RICK, it is possible that Pseudo-ICE induces oligomerization of RICK leading to activation of NF- $\kappa$ B. Oligomerization of RIP and RICK, which interact directly with IKK- $\gamma$, an essential component of the IKK complex, has been recently proposed as a mechanism by which upstream regulators 
transmit their activation signals to the IKK complex leading its activation. ${ }^{40,41}$

This study, together with those of Thome et $a l^{23}$ and Humke et al. $^{24}$ represent the first studies which identified potential intracellular regulators of caspase-1 activation. The characterization of additional interacting partners for group I caspases involved in cytokine production rather than in apoptosis, such as caspases-1, $-4,-5$ and $-13,{ }^{12}$ may help to better understand the mechanisms responsible for their activation. Finding out how group I caspases are regulated is an important step in the discovery of new antiinflammatory therapeutics.

\section{Materials and Methods}

\section{Isolation of Pseudo-ICE and ICEBERG cDNAs}

The nucleotide sequences of Pseudo-ICE and ICEBERG cDNAs were identified by searching the Genbank EST databases for sequences similar to the prodomain of caspase- 1 using the tBLASTn program. Two EST clones whose accession numbers are AA070591 and AA046000 corresponding to Pseudo-ICE and ICEBERG, respectively, were identified and obtained from the I.M.A.G.E. consortium (Washington University School of Medicine, St Louis, MO, USA) and their entire nucleotide sequence was determined by automated sequencing.

Based on the sequence of the EST clone AA070591, primers were designed (Figure 1) and used to amplify Pseudo-ICE cDNA by PCR from different human tissues and cell lines. Pseudo-ICE CDNAs were cloned into pcDNA3 (Invitrogen, Carlsbad, CA, USA), and sequenced. Similar procedures were performed to isolate and verify the sequence of ICEBERG cDNA.

\section{Chromosomal mapping}

BLASTn program was used to search for similarities between the full length sequence of Pseudo-ICE or ICEBERG and Genbank HTGS.

\section{Origin and construction of expression and reporter plasmids}

The entire reading frame of Pseudo-ICE, ICEBERG and caspase- $1^{42}$ were amplified by PCR using complementary PCR adaptor primers spanning the initiation and stop codons of these genes.

T7, Flag, enhanced green-fluorescent protein and GST-fused genes were made by cloning PCR products in-frame into the expression vector pcDNA3, pCMV2 (Sigma, Saint-Louis, MO, USA), pEGFP-C1, pEGFP-N1 (Clontech, Palo Alto, CA, USA) and pGEX-5X 3 (Amersham Pharmacia Biotech, San Francisco, CA, USA), respectively. CDNAs for T7-Pseudo-ICE, -ICEBERG and -caspase-1 $C$ to $A$ active site mutant were generated by PCR and then subcloned into pMSCVneo retroviral vector (Clontech).

Expression vectors for human Apaf-1, cCLAP, CRADD, caspase-8, caspase-10, and caspase-9 $C$ to $A$ have been described before. ${ }^{17,29,43,44}$ RICK expression construct was a generous gift from Dr. G Nunez (University of Michigan, Ann Arbor, MI, USA). Kinase inactive mutant of IKK- $\alpha$ were kindly provided by $\mathrm{Dr}$ WC Greene (University of California, San Francisco, CA, USA). The $5 \mathrm{x} \kappa \mathrm{B}$-luciferase reporter plasmid was from Stratagene (La Jolla, CA, USA). All other cDNAs used in this study were generated by PCR using appropriate PCR primers and subcloned into appropriate expression constructs.

\section{GST fusion proteins and in vitro interaction assay}

The GST fusion proteins were expressed in $E$. coli $\mathrm{DH} 5-\alpha$ bacteria (Life Technologies, Rockville, MD, USA) incubated for $2 \mathrm{~h}$ at $30^{\circ} \mathrm{C}$ in the presence of $0.5 \mathrm{mM}$ of isopropyl-1-thio- $\beta$-D-galactoside. Cells were sonicated in GST buffer composed of $20 \mathrm{mM} \mathrm{N}$-(2-hydroxyethyl)piperazine- $\mathrm{N}^{\prime}$-(2-ethanesulfonic acid), $\mathrm{pH}$ 7.6, $1.5 \mathrm{mM}$ $\mathrm{MgCl}_{2}, 100 \mathrm{mM} \mathrm{NaCl}, 1 \mathrm{mM}$ dithiotreitol, $1 \%$ Triton X-100 and phenyl-methyl-sulfonyl-fluoride. Cells were then centrifuged at $10000 \times g$ for $15 \mathrm{~min}$ and supernatants were incubated for $2 \mathrm{~h}$ at $4{ }^{\circ} \mathrm{C}$ with gluthatione Sepharose $4 \mathrm{~B}$ resin (Amersham Pharmacia Biotech). The protein-bound resin ( $30 \mu \mathrm{l}$ ) was washed with GST buffer and incubated overnight at $4{ }^{\circ} \mathrm{C}$ in the presence of $5 \mu \mathrm{l}$ of ${ }^{35} \mathrm{~S}$-labeled in vitro-translated products. Labeled proteins were prepared from pcDNA3 constructs by in vitro transcription and translation in the presence of ${ }^{35} \mathrm{~S}$-methionine using T7-coupled transcription/translation TNT kit according to the manufacturer's instructions (Promega, Madison, WI, USA). Samples of the protein-bound resins were washed three times in GST buffer, boiled in sodium dodecyl sulfate Laemmli sample buffer and then fractionated by electrophoresis on a sodium dodecyl sulfate-polyacrylamide gel. Proteins were then visualized by autoradiography.

\section{In vivo interaction assay}

Human embryonic kidney 293 T cells, were cultured in $100 \mathrm{~mm}$ dishes in Dulbecco modified essential medium supplemented with $10 \%$ fetal bovine serum and antibiotics (all from Life Technologies) defined as DMEM/FBS. When cells reached $50 \%$ confluency, they were transiently co-transfected with various amounts of T7-pcDNA3 and Flag-pCMV2 vectors in OptiMEM using the lipofectamine method according to the manufacturer's recommendations (both from Life Technologies). The expression vectors used and their respective amount are indicated in the legend of Figures 2 and 3 . Twelve hours after transfection, OptiMEM was replaced with DMEM/FBS. Twentyfour hours later, cells were lysed in $300 \mu$ l of a buffer containing $25 \mathrm{mM}$ tris(hydroxymethyl)aminomethane, $\mathrm{pH} 7.6,150 \mathrm{mM} \mathrm{NaCl}, 1 \%$ nonidetP40, and phenyl-methyl-sulfonyl-fluoride. Samples were centrifuged. One third of the supernatant was put aside to verify by Western blot the expression of the proteins. The remaining $200 \mu$ l of supernatant were incubated for $2 \mathrm{~h}$ at $4{ }^{\circ} \mathrm{C}$ with anti-Flag M5 plus $\mathrm{M} 2$ monoclonal antibodies (Sigma). The immune complexes were precipitated overnight at $4^{\circ} \mathrm{C}$ with protein-G Sepharose (Amersham Pharmacia Biotech), washed extensively and then eluted by boiling in Laemmli sample buffer. The eluted proteins were resolved by polyacrylamide gel and detected by Western blot analysis with horseradish peroxidase-conjugated anti-T7 antibody (Novagen, Madison, WI, USA). Bands were then detected using enhanced chemiluminescence kit (Amersham Pharmacia Biotech).

\section{Transfection of THP1 cells and assay of IL-1 $\beta$ and IL-1 receptor antagonist secretion}

The monocytic cell line THP1 was cultured in RPMI 1640 supplemented with $10 \mathrm{mM} \mathrm{N}$-(2-hydroxyethyl)piperazine-N'-(2-ethanesulfonic acid), $1 \mathrm{mM}$ sodium pyruvate, $55 \mu \mathrm{M} \beta$-mercaptoethanol, $10 \%$ fetal bovine serum, antibiotics (all from Life Technologies) and $5 \mathrm{ng} / \mathrm{ml}$ macrophage-colony stimulating factor (Sigma). The amphotropic packaging cell line Phoenix (G.P. Nolan's laboratory, Stanford University Medical Center, Stanford, CA, USA) was transfected with pMSCVneo vectors using the calcium phosphate/chloroquine method. ${ }^{45}$ Forty-eight hours after transfection, culture supernatants containing retroviral particles were collected and filtered through 
$0.45 \mu \mathrm{m}$ membrane. THP1 cells $\left(1 \times 10^{6}\right.$ cells/well $)$ were then centrifuged in 6-well plate for $45 \mathrm{~min}$ at 1800 r.p.m. at $32^{\circ} \mathrm{C}$ in the presence of $3 \mathrm{ml}$ of retrovirus-enriched supernatant supplemented in $4 \mu \mathrm{g} / \mathrm{ml}$ of polybrene (Sigma). Plates were placed back in a $\mathrm{CO}_{2}$ incubator at $32^{\circ} \mathrm{C}$ for $1.5 \mathrm{~h}$. Supernatants were replaced for fresh retrovirus-enriched medium. THP1 cells were subjected to a total of three cycles of infection followed by $48 \mathrm{~h}$ of culture in THP1 growth medium described above. Cells were then selected using $1 \mathrm{mg} / \mathrm{ml}$ neomycin (Life Technologies). After 2 weeks of culture, viable THP1 cells were sedimented and cultured in 96-well plates in the presence of neomycine.

After several weeks of culture, the expression of transgenes was verified by Western blotting of mass culture lysates.

To assay for IL- $1 \beta$ and IL-1 receptor antagonist, cells $\left(0.75 \times 10^{6}\right.$ cells $/ \mathrm{ml}$ ) were cultured for $24 \mathrm{~h}$ with THP1 medium without fetal bovine serum and macrophage colony-stimulating factor and were incubated for $4 \mathrm{~h}$ with 100 units $/ \mathrm{ml}$ of IFN- $\gamma$ and then for $18 \mathrm{~h}$ with $10 \mu \mathrm{g} / \mathrm{ml}$ of LPS. Supernatants diluted at $1 / 2-1 / 4$ or $1 / 10-1 / 40$ were used to quantify IL-1 $\beta$ or IL-1 receptor antagonist, respectively, by enzymelinked immunosorbent assay (R\&D systems, Minneapolis, MN, USA).

\section{Apoptosis assay}

MCF-7 Fas cells, breast adenocarcinoma cells stably transfected with Fas receptor, were seeded in triplicate at $0.05 \times 10^{6}$ cells/well in 6 -well plates in DMEM/FBS. Thirty-six hours later, cells were transfected with $0.2 \mu \mathrm{g} \mathrm{pRSC}$ LacZ reporter plasmid, $0.8 \mu \mathrm{g} \mathrm{T7}$ Pseudo-ICE, ICEBERG, or caspase-9 $\mathrm{C}$ to $\mathrm{A}$ together with $4 \mu \mathrm{l}$ of lipofectamine in $1 \mathrm{ml}$ of OptiMEM. Eight hours after the beginning of transfection, OptiMEM medium was replaced with DMEM/FBS and 2 or $10 \mathrm{ng} / \mathrm{ml}$ of TNF- $\alpha$ were added to the cultures for $12 \mathrm{~h}$. Cells were then stained in situ for $\beta$-galactosidase activity using the $\beta$-Gal staining kit from Invitrogen. The proportions of apoptotic cells were evaluated by counting the numbers of stained normal and apoptotic cells. The cells from the third remaining well were collected and lysed. Cell lysates were used to verify the expression of the transgenes.

\section{Determination of intracellular localization}

MCF-7 Fas cells were transfected with $1 \mu \mathrm{g}$ of Pseudo-ICE or ICEBERG pEGFP-C1 or -N1 as described above. Twenty-four hours after the beginning of the transfection, the intracellular localization was evaluated by observing the cells using a fluorescence microscope.

\section{Quantification of NF- $\kappa$ B activity}

$293 \mathrm{~T}$ cells were seeded in triplicate at $0.3 \times 10^{6}$ cells/well in 12-well plates in DMEM/FBS. Twenty-four hours later, cells were transfected with various expression vectors plus $0.025 \mu \mathrm{g} 5 \mathrm{x} \kappa \mathrm{B}$-luciferase and $0.2 \mu \mathrm{g} \mathrm{pRSC}$-LacZ reporter plasmids, together with $3 \mu \mathrm{l}$ of lipofectamine in $1 \mathrm{ml}$ of OptiMEM. The expression vectors used and their respective amount are indicated in the legend of Figure 6 . In each well the total amount of T7 pcDNA3 and Flag pCMV2 expression vectors was kept constant at $0.7 \mu \mathrm{g}$ by addition of empty vector. OptiMEM medium was replaced with DMEM/FBS $8 \mathrm{~h}$ after transfection. Sixteen hours after the change of medium, the cells were collected, washed in phosphate buffer saline and lysed using lysis buffer from Promega's luciferase assay system kit. In some experiments, cells were treated for $6 \mathrm{~h}$ with $20 \mathrm{ng} / \mathrm{ml}$ of TNF- $\alpha$ prior to harvesting.

NF- $\kappa$ B activity was assayed on $5 \mu$ l of cell lysates by chemiluminescence as per the instructions of Promega. To normalize for transfection efficiency, cell lysates were also subjected to $\beta$ - galactosidase spectrophotometric assay. In brief, $10 \mu \mathrm{l}$ of cell lysate were incubated for $15 \mathrm{~min}$ at $37^{\circ} \mathrm{C}$ with $290 \mu \mathrm{l}$ of a solution containing $0.9 \mathrm{mg} / \mathrm{ml}$ o-nitrophenyl- $\beta$-D-galactopyranoside, $1 \mathrm{mM} \mathrm{MgCl} 2,45 \mathrm{mM}$ $\beta$-mercaptoethanol, $100 \mathrm{mM}$ sodium phosphate, $\mathrm{pH}$ 7.5. The reaction was stopped by addition of $500 \mu \mathrm{l}$ of $\mathrm{Na}_{2} \mathrm{CO}_{3}$ at $1 \mathrm{M}$. The optical density was read at a wavelength of $420 \mathrm{~nm}$. Results are expressed as relative luciferase units per second/optical density for $\beta$-galactosidase activity.

\section{Accession numbers}

The nucleotide sequences reported here have been submitted to the Genbank/EMBL Data Bank (accession number AF367017).

\section{Acknowledgements}

This work was supported by NIH Research Grant AG14357 (to ES Alnemri). A Druilhe was supported by postdoctoral fellowships from the Association pour la Recherche contre le Cancer (ARC), and from the Institut National de la Santé et de la Recherche Médicale (INSERM), both in Paris, France. We thank Adriana Eramo and Dr. Gaetano Romano for technical assistance in retroviral gene transfer technology. SM Srinivasula is a Special Fellow of The Leukemia and Lymphoma Society.

\section{References}

1. Cerretti DP, Kozlosky CJ, Mosley B, Nelson N, Van Ness K, Greenstreet TA, March CJ, Kronheim SR, Druck T, Cannizzaro LA, Huebner K and Black RA (1992) Molecular cloning of the interleukin-1 beta converting enzyme. Science 256: $97-100$

2. Thornberry NA, Bull HG, Calaycay JR, Chapman KT, Howard AD, Kostura MJ, Miller DK, Molineaux SM, Weidner JR, Aunins J, Elliston KO, Ayala JM, Casano FJ, Chin J, Ding GJ-F, Egger LA, Gaffney EP, Limjuco G, Palyha OC, Raju SM, Rolando AM, Salley JP, Yamin T-T, Lee TD, Shively JE, MacCross M, Mumford RA, Schmidt JA and Tocci MJ (1992) A novel heterodimeric cysteine protease is required for interleukin-1 $\beta$ processing in monocytes. Nature 356: 768-774

3. Ghayur T, Banerjee S, Hugunin M, Butler D, Herzog L, Carter A, Quintal L, Sekut L, Talanian R, Paskind M, Wong W, Kamen R, Tracey D and Allen H (1997) Caspase-1 processes IFN-gamma-inducing factor and regulates LPS-induced IFN-gamma production. Nature 386: 619-623

4. Li P, Allen H, Banerjee S, Franklin S, Herzog L, Johnston C, McDowell J, Paskind M, Rodman L, Salfeld J, Towne E, Tracey D, Wardell S, Wei F-Y, Wong W, Kamen $R$ and Seshadri T (1995) Mice deficient in IL-1 $\beta$-converting enzyme are defective in production of mature IL-1 $\beta$ and resistant to endotoxic shock. Cell 80: 401-411

5. Kuida K, Lippke JA, Ku G, Harding MW, Livingston DJ, Su MS-S and Flavell RA (1995) Altered cytokine export and apoptosis in mice deficient in interleukin-1 $\beta$ converting enzyme. Science 267: 2000-2003

6. Norman J, Yang J, Fink G, Carter G, Ku G, Denham W and Livingston D (1997) Severity and mortality of experimental pancreatitis are dependent on interleukin1 converting enzyme (ICE). J. Interferon Cytokine Res. 17: 113-118

7. Fantuzzi G, Puren AJ, Harding MW, Livingston DJ and Dinarello CA (1998) Interleukin-18 regulation of interferon $\gamma$ production and cell proliferation as shown in interleukin-1 $\beta$-converting enzyme (caspase-1)-deficient mice. Blood 91: 2118-2125

8. Furlan R, Martino G, Galbiati F, Poliani PL, Smiroldo S, Bergami A, Desina G, Comi G, Flavell R, Su MS and Adorini L (1999) Caspase-1 regulates the inflammatory process leading to autoimmune demyelination. J. Immunol. 163: 2403-2409

9. Yuan J, Shaham S, Ledoux S, Ellis HM and Horvitz HR(1993) The C.elegans cell death gene ced-3 encodes a protein similar to mammalian interleukin-1 betaconverting enzyme. Cell 75: 641-652

10. Ellis RE, Yuan JY and Horvitz HR (1991) Mechanisms and functions of cell death. Annu. Rev. Cell Biol. 7: 663-698 
11. Alnemri ES (1997) Mammalian cell death protease: a family of highly conserved aspartate specific cysteine proteases. J. Cell. Biochem. 64: 33-42

12. Nicholson DW (1999) Caspase structure, proteolytic substrates, and function during apoptotic cell death. Cell Death Differ. 6: 1028-1042

13. Alnemri ES, Livingston DJ, Nicholson DW, Salvesen G, Thornberry NA, Wong WW and Yuan J (1996) Human ICE/CED-3 protease nomenclature. Cell 87: 171

14. Muzio M, Salvesen GS and Dixit VM (1997) FLICE induced apoptosis in a cellfree system. J. Biol. Chem. 272: 2952-2956

15. Scaffidi C, Fulda S, Srinivasan A, Friesen C, Li F, Tomaselli KJ, Debatin K-M, Krammer PH and Peter ME (1998) Two CD95 (APO-1/Fas) signaling pathways. EMBO J. 17: 1675-1687

16. Fernandes-Alnemri T, Armstrong RC, Krebs J, Srinivasula SM, Wang L, Bullrich F, Fritz LC, Trapani JA, Tomaselli KJ, Litwack G and Alnemri ES (1996) In vitro activation of CPP32 and Mch3 by Mch4, a novel human apoptotic cysteine protease containing two FADD-like domains. Proc. Natl. Acad. Sci. USA 93: 7464-7469

17. Li P, Nijhawan D, Budihardjo I, Srinivasula SM, Ahmad M, Alnemri ES and Wang $X$ (1997) Cytochrome $c$ and dATP-dependent formation of Apaf-1/caspase- 9 complex initiates an apoptotic protease cascade. Cell 91: 479-489

18. Srinivasula SM, Ahmad M, Fernandes-Alnemri T and Alnemri ES (1998) Autoactivation of procaspase-9 by Apaf-1-mediated oligomerization. Mol. Cell 1: $1-20$

19. Salvesen GS and Dixit VM (1999) Caspase activation: the induced-proximity model. Proc. Natl. Acad. Sci. USA 96: 10964-10967

20. Muzio M, Stockwell BR, Stennicke HR, Salvesen GS and Dixit VM (1998) An induced proximity model for caspase-8 activation. J. Biol. Chem. 273: $2926-$ 2930

21. Hofmann K (1999) The modular nature of apoptotic signaling proteins. Cell. Mol. Life. Sci. 55: 1113-1128

22. Gu Y, Wu J, Faucheu C, Lalanne J-L, Diu A, Livingston DJ and Su MS-S (1995) Interleukin-1 $\beta$ converting enzyme requires oligomerization for activity of processed forms in vivo. EMBO J. 14: 1923-1931

23. Thome M, Hofmann K, Burns K, Martinon F, Bodmer J-L, Mattmann C and Tschopp J (1998) Identification of CARDIAK, a RIP-like kinase that associates with caspase-1. Curr. Biol. 8: 885-888

24. Humke EW, Shriver SK, Starovasnik MA, Fairbrother WJ and Dixit VM (2000) ICEBERG: a novel inhibitor of interleukin-1 $\beta$ generation. Cell 103: 99-111

25. Kline JN, Fisher PA, Monick MM and Hunninghake GW (1995) Regulation of interleukin-1 receptor antagonist by Th1 and Th2 cytokines. Am. J. Physiol. 269: L92-L98

26. Mao P-L, Jiang Y, Yu Wee B and Porter AJ (1998) Activation of caspase-1 in the nucleus requires nuclear translocation of pro-caspase- 1 mediated by its prodomain. J. Biol. Chem. 273: 23621-23624

27. Guiet $C$ and Vito $P(2000)$ Caspase recruitment domain (CARD)-dependent cytoplasmic filaments mediate bcl10-induced NF- $k$ B activation. J. Cell Biol. 148: $1131-1139$

28. Siegel RM, Martin DA, Zheng L, Ng SY, Bertin J, Cohen J and Lenardo MJ (1998) Death-effector filaments: novel cytoplasmic structures that recruit caspases and trigger apoptosis. J. Cell Biol. 141: 1243-1253

29. Srinivasula SM, Ahmad M, Lin J-H, Poyet J-L, Fernandes-Alnemri T, Tsichlis PN and Alnemri ES (1999) CLAP, a novel caspase recruitment domain-containing protein in the tumor necrosis factor receptor pathway, regulates NF-kappaB activation and apoptosis. J. Biol. Chem. 274: 17946-17954
30. McCarthy JV, Ni J and Dixit VM (1998) RIP2 is a novel NF- $\kappa$ B-activating and cell death-inducing kinase. J. Biol. Chem. 273: 16968-16975

31. Hofer-Warbinek R, Schmid JA, Stehlik C, Binder BR, Lipp J and de Martin R (2000) Activation of NF-kappa B by XIAP, the X-chromosome-linked inhibitor of apoptosis, in endothelial cells involves TAK1. J. Biol. Chem. 275: 22064-22068

32. Costanzo A, Guiet $C$ and Vito $P$ (1999) c-E10 is a caspase-recruiting domaincontaining protein that interacts with components of death receptors signaling pathway and activates nuclear factor-kappaB. J. Biol. Chem. 274:20127-20132

33. Koseki T, Inohara N, Chen S, Carrio R, Merino J, Hottiger MO, Nabel GJ and Nunez G (1999) CIPER, a novel NF kappaB-activating protein containing a caspase recruitment domain with homology to Herpesvirus-2 protein E10. J. Biol. Chem. 274: 9955-9961

34. Willis TG, Jadayel DM, Du MQ, Peng H, Perry AR, Abdul-Rauf M, Price H, Karran L, Majekodunmi O, Wlodarska I, Pan L, Crook T, Hamoudi R, Isaacson PG and Dyer MJ (1999) Bcl10 is involved in $t(1 ; 14)(p 22 ; q 32)$ of MALT B cell lymphoma and mutated in multiple tumor types. Cell 96: 35-45

35. Zhang Q, Siebert R, Yan M, Hinzmann B, Cui X, Xue L, Rakestraw KM, Naeve CW, Beckmann G, Weisenburger DD, SangerWG, Nowotny H, Vesely M, CalletBauchu E, Salles G, Dixit VM, Rosenthal A, Schlegelberger B and Morris SW (1999) Inactivating mutations and overexpression of BCL10, a caspase recruitment domain-containing gene, in MALT Iymphoma with $\mathrm{t}(1 ; 14)(\mathrm{p} 22 ; \mathrm{q} 32)$. Nat. Genet. 22: 63-68

36. Bertin J, Nir WJ, Fischer CM, Tayber OV, Errada PR, Grant JR, Keilty JJ, Gosselin ML, Robison KE, Wong GH, Glucksmann MA and DiStefano PS (1999) Human CARD4 protein is a novel CED-4/Apaf- 1 cell death family member that activates NF-kappa B. J. Biol. Chem. 274: 12995-12958

37. Inohara N, Koseki T, delPeso L, HuY, Yee C, Chen S, Carrio R, Merino J, Liu D, Ni $\mathrm{J}$ and Nunez G (1999) Nod1, an Apaf-1-like activator of caspase-9 and nuclear factor- $\kappa$ B. J. Biol. Chem. 274: 14560-14567

38. Pahl HL (1999) Activators and target genes of Rel/NF- $\kappa$ B transcription factors. Oncogene 18: 6853-6866

39. Karin M (1999) How NF- $\kappa$ B is activated: the role of $\mathrm{I}_{\kappa} \mathrm{B}$ kinase (IKK) complex. Oncogene 18: 6867-6874

40. PoyetJL, Srinivasula SM, Lin JH, Fernandes-Alnemri T, Yamaoka S, Tsichlis PN and Alnemri ES (2000) Activation of $\mathrm{I} \kappa \mathrm{B}$ kinases by RIP via IKK $\gamma / \mathrm{NEMO}$ mediated oligomerization. J. Biol. Chem. 275: 37966-37977

41. Inohara N, Koseki T, Lin J, del Peso L, Lucas PC, Chen FF, Ogura Y and Nunez G (2000) An induced proximity model for NF-kappa B activation in the Nod1/RICK and RIP signaling pathways. J. Biol. Chem. 275: 27823-27831

42. Alnemri ES, Fernandes-Alnemri T and Litwack G (1995) Cloning and expression of four novel isoforms of human interleukin-1 beta converting enzyme with different apoptotic activities. J. Biol. Chem. 270: 4312-4317

43. MacFarlane M, Ahmad M, Srinivasula SM, Fernandes-Alnemri T, Cohen GM and Alnemri ES (1997) Identification and molecular cloning of two novel receptors for the cytotoxic ligand TRAIL. J. Biol. Chem. 272: 25417-25420

44. Ahmad M, Srinivasula SM, Wang L, Talanian RV, Litwack G, Fernandes-Alnemri T and Alnemri ES (1997) CRADD, a novel human apoptotic adaptor molecule for caspase-2, and FasL/tumor necrosis factor receptor-interacting protein RIP. Cancer Res. 57: 615-619

45. Kinsella TM and Nolan GP (1996) Episomal vectors rapidly and stably produce high-titer recombinant retrovirus. Hum. Gene Ther. 7: 1405-1413 